\title{
Clustered Distribution and Variability in Kinetics of Transient K Channels in Molluscan Neuron Cell Bodies
}

\author{
Brett A. Premack, ${ }^{1}$ Stuart Thompson, ${ }^{1}$ and Julie Coombs-Hahn ${ }^{2}$ \\ ${ }^{1 H}$ Hopkins Marine Station, Stanford University, Pacific Grove, California 93950, and '2Department of Zoology, University of \\ Washington, Seattle, Washington 98195
}

The spatial distribution of transient $K$ current, $I_{A}$, was studied using a combination of patch-clamp and whole-cell voltageclamp techniques. The average $I_{\mathrm{A}}$ current density in somatic patches is $\mathbf{0 . 6 4}$ times the current density in the entire axotomized cell body, a finding which suggests that the axon hillock or initial segment of the axon has a higher concentration of $I_{A}$ channels than much of soma. The highest density of active channels during the peak $I_{A}$ is $1 / \mu \mathrm{m}^{2}$ at a membrane voltage of $-20 \mathrm{mV}$. There is no evidence for a gradient in the distribution of $I_{A}$ channels in the cell body, but the channels are not evenly distributed. The variability in the number of channels per patch for multiple patches on the same neuron is much higher than expected for a random distribution. Statistical analysis of the data yields a coefficient of dispersion of 8.1, a value indicating a high degree of clustering. The utility of this statistic for evaluating channel distributions is discussed. Several lines of evidence suggest that the upper limit for the area of $I_{A}$ channel clusters is approximately $250 \mu \mathbf{m}^{2}$.

Single-channel currents attributed to $I_{A}$ were recorded in the cell-attached configuration. The voltage dependence of channel opening and inactivation are the same as measured in whole-cell voltage-clamp experiments. The single-channel conductance is about 9 pS in normal saline. Patches 9$30 \mu \mathrm{m}^{2}$ in areas that contain $I_{A}$ channels are often devoid of other $K$ channel types, suggesting that $I_{A}$ channels can occur in isochannel clusters.

$I_{A}$ inactivation follows an exponential time course in all of the neurons examined, but the time constant of inactivation ranges from 25 to $560 \mathrm{msec}$ in different cells. The voltage dependence of activation and inactivation and the reversal potential of the current are approximately the same in all cells. When multiple patches on the same neuron are studied, it is found that $I_{A}$ inactivates exponentially with approximately the same time constant in each patch, regardless of patch area. The data suggest that each neuron expresses predominantly, and perhaps exclusively, a single type of $I_{A}$ channel with distinct kinetic properties. The wide range of $I_{A}$ inactivation time constants observed in different cells suggests that a large number of channel types are available for expression. Possible mechanisms for generating diversity in channel types are discussed.

\footnotetext{
Received Nov. 23, 1988; revised May 1, 1989; accepted May 8, 1989.

We thank R. Aldrich and S. Wang for helpful discussions. The research was conducted at the Hopkins Marine Station, and we thank the staff of that institution for their support. Funded by USPHS grant NS 14514 to S.T.

Correspondence should be addressed to Stuart Thompson at the above address. Copyright (C) 1989 Society for Neuroscience 0270-6474/89/114089-11\$02.00/0
}

The processing of information by neurons is influenced by the types of membrane ion channels that are expressed by the cell, their relative abundance, and the spatial distribution of channels across the neuronal surface. These factors interact to determine the response to synaptic input, the spike threshold and waveform, and the repetitive firing characteristics of the cell. The transient potassium current, termed $I_{\mathrm{A}}$ by Connor and Stevens (1971), has a strong effect on these cellular processes because it begins to activate at subthreshold voltages and influences both the approach to threshold at the onset of stimulation and the firing rate (Connor and Stevens, 1971; Neher, 1971; see Adams et al., 1980; Thompson and Aldrich, 1980). In molluscan ganglia the kinetics and relative amplitude of $I_{\mathrm{A}}$ differ between cells (Connor and Stevens, 1971; Neher, 1971; Serrano, 1982), and similar variability appears to occur in other preparations (Rudy, 1988).

The spatial distribution of $I_{\mathrm{A}}$ and both cellular and regional differences in the kinetics of the current were studied in molluscan neuron cell bodies using a large patch-recording method in combination with 2 microelectrode voltage clamp. Singlechannel currents were also recorded from small patches in the cell-attached configuration after the formation of a gigaseal.

\section{Materials and Methods}

The cell bodies of identified neurons were acutely isolated from the pedal and pleural ganglia of adult specimens of the molluscan species Doriopsilla albopunctata and Anisodoris nobilis using methods described by Thompson and Coombs (1988). The isolation procedure leaves a remnant of axon, 100-200 $\mu \mathrm{m}$ in length, attached to the soma (soma diameter, $200-350 \mu \mathrm{m}$ ). Neurons were bathed in saline of the following composition (mM): $460 \mathrm{NaCl}, 10 \mathrm{KCl}, 10 \mathrm{CaCl}_{2}, 50 \mathrm{MgCl}_{2}, 10 \mathrm{HEPES}$ (pH 7.8). The resting potential in this saline is approximately $-40 \mathrm{mV}$. A low-K saline was used on occasion (in $\mathrm{mm}$ ): $469.9 \mathrm{NaCl}, 0.1 \mathrm{KCl}$, $10 \mathrm{CaCl}_{2}, 50 \mathrm{MgCl}_{2}, 10 \mathrm{HEPES}, \mathrm{pH} 7.8$. The temperature was maintained at $15^{\circ} \mathrm{C}$.

Voltage-clamp and large patch-current recording. Standard 2-microelectrode voltage-clamp techniques were used. Micropipettes were filled with $3 \mathrm{M} \mathrm{KCl}$ and had resistances of 2-5 M . Membrane voltage was measured differentially between one of the intracellular microelectrodes and a voltage electrode in the bath. Whole-cell current was recorded with a virtual-ground amplifier contacting the bath via a separate electrode. There was no evidence of escape in the whole-cell current record during depolarizing voltage steps in isolated cells, indicating that the cell body and axon remnant were adequately space-clamped. Assuming an average series resistance of $2 \mathrm{~K} \Omega$ and a maximum $I_{\mathrm{A}}$ of 500 $\mathrm{nA}$, the maximum series resistance error in recorded voltage is about $1 \mathrm{mV}$.

Macroscopic currents were recorded from patches of soma membrane using large extracellular pipettes in the cell-attached configuration. Details of the method are given in Thompson and Coombs (1988) and Johnson and Thompson (1989). Various patch pipettes were employed with orifices between 2 and $20 \mu \mathrm{m}$ in diameter. Large-diameter pipettes 
were particularly useful for studying general trends in channel distribution across the cell body surface, while small-diameter pipettes were useful for investigating the nature of channel clusters. Pipettes were filled with external saline and sealed to the membrane by gentle suction until the resistance increased from about $300 \mathrm{~K} \Omega$ to between 10 and $100 \mathrm{M} \Omega$, after which the suction was released. Patch current was recorded with a virtual-ground amplifier employing a $100 \mathrm{M} \Omega$ feedback resistor that was referenced to the bath voltage follower. This configuration provided correction for changes in bath voltage that occur during large whole-cell currents. Errors in patch-current measurement due to the finite resistance of the seal are negligible because the lumen of the pipette is maintained at the bath potential, and because the seal resistance is much higher than the pipette resistance (Johnson and Thompson, 1989). Care was taken to avoid pulling a finger of membrane into the pipette since this can lead to errors in voltage control due to increased access resistance. Data were accepted only if the seal resistance and the area of the patch remained relatively constant, varying less than $5 \%$, over the course of an experiment. The patch pipette could be reused and repeatedly applied to points from the soma cap, antipodal to the emergence of the axon, to midway between the axon and the equator of the cell body. Points on the axon hillock or initial axon could occasionally be reached after aspirating away adherent cells and connective tissue, but this difficult procedure was not used routinely. Appropriately filtered records of membrane voltage, whole-cell current, and patch current were digitized and stored on a laboratory computer (DEC 11/ 23) at adjustable sampling rates. Exponential relaxations were fit to the inactivating phase of $I_{\mathrm{A}}$ by the method of least squares (algorithm of Marquardt, 1963, as described by Bevington, 1969). Computed curves were displayed along with the data points on the computer terminal to allow the accuracy of the fitting procedure to be verified by inspection.

Single-channel recording. Currents were also recorded from smaller membrane patches after the formation of a gigaseal. Small patch pipettes (resistance, 2-10 M $\Omega$ ) were filled with normal external saline or low-K saline. In some experiments, the solution in the patch electrode contained 100 mm TEA (prepared by equimolar substitution of TEA.Cl for $\mathrm{NaCl}$ ) in order to block the voltage-dependent delayed $\mathrm{K}$ current, $I_{\mathrm{K}}$ (Thompson, 1977). Recordings were made in the cell-attached configuration using a List EPC/7 amplifier. Desheathed neurons were treated with $0.1 \%$ trypsin (Sigma Type IX) in Ca-free saline for $20 \mathrm{~min}$ at $15^{\circ} \mathrm{C}$ prior to recording. The enzyme treatment increased the success rate for the formation of tight seals. In most of these experiments, a single intracellular microelectrode was used to monitor cell voltage, and therefore the absolute membrane potential for each patch was known. Current records were filtered at $1 \mathrm{kHz}$ (8-pole Bessel filter) and digitized at rates of $1-10 \mathrm{kHz}$ with 12-bit resolution using an IBM AT and pClamp software.

Current separation. The transient potassium current, $I_{\mathrm{A}}$, was separated from other components of membrane current by taking advantage of the unique voltage dependence of $I_{\mathrm{A}}$ activation and inactivation. In these neurons, $I_{\mathrm{A}}$ activates at more negative voltages than the delayed $\mathrm{K}$ currents or the inward $\mathrm{Na}$ and $\mathrm{Ca}$ currents. During steps to voltages between -50 and $-20 \mathrm{mV}$ from conditioning voltages of -90 or -100 $\mathrm{mV}, I_{\mathrm{A}}$ can be studied without significant contamination from these other currents (Adams et al., 1980; Thompson and Aldrich, 1980).

Measurement of surface area. In large patch experiments, the area of the patch and of the entire axotomized cell body was estimated by measuring capacity currents during a triangle-wave voltage command, assuming a unit capacitance of $1 \mu \mathrm{F} / \mathrm{cm}^{2}$. Details of the method are given in Thompson and Coombs (1988) and Johnson and Thompson (1989). Capacitance measurements were made before and after each experiment in order to insure that the patch area remained constant. In gigaseal patch experiments, the area of the patch was read from the dial on the recording amplifier after cancellation of the membrane capacity transient.

\section{Results}

Spatial distribution of $\mathrm{I}_{\cdot A}$ in the soma

Transient $\mathrm{K}$ currents, recorded simultaneously from an axotomized neuron cell body and from a large membrane patch located at the axon hillock, are shown in Figure 1. The currents were activated by steps to $-30 \mathrm{mV}$ following a series of 500 msec conditioning steps to voltages between -50 and $-90 \mathrm{mV}$. The whole cell and patch currents follow similar time courses and increase in parallel as $I_{\mathrm{A}}$ inactivation is progressively removed. In this example, the area of the patch is equal to $6 \times$ $10^{-4}$ times the whole-cell area and the maximum $I_{\mathrm{A}}$ current density in the patch during the step from $-90 \mathrm{mV}(0.16 \mathrm{pA} /$ $\left.\mu \mathrm{m}^{2}\right)$ is slightly greater than the current density in the entire axotomized cell $\left(0.15 \mathrm{pA} / \mu \mathrm{m}^{2}\right)$. The number of channels activated by the step to $-30 \mathrm{mV}$ from $-90 \mathrm{mV}$ was estimated by dividing the peak current by the amplitude of the single-channel current at the same voltage ( $0.33 \mathrm{pA}$; see Fig. 9$)$. Approximately $1.3 \times 10^{3}$ channels are activated in the patch, while $2.9 \times 10^{6}$ channels are activated in the whole cell body. These calculated values are likely to underestimate the actual channel number because not all channels are open at the peak current.

The spatial distribution of $I_{\mathrm{A}}$ was studied by comparing current densities in patches at different locations on 47 individual neurons. Large patch pipettes (membrane area, $31-3750 \mu \mathrm{m}^{2}$, equal to between $8 \times 10^{-5}$ and $6 \times 10^{-3}$ times the whole cell area) were used for this purpose. Recordings were made from the soma cap, opposite the emergence of the axon, to the base of the soma at the axon hillock. The peak amplitudes of patch currents and whole-cell currents were measured during steps to $-20 \mathrm{mV}$ from a conditioning voltage of $-90 \mathrm{mV}$ and scaled by membrane area in order to calculate current densities. The ratio of patch-current density to whole-cell current density was used to construct the histogram in Figure 2. A value of 1 means that the current density in the patch is equal to the current density in the entire axotomized cell, while larger or smaller values indicate that the patch is enriched or lacking in current relative to the cell body average. The ratio of patch to wholecell current density is quite variable and has a mean value of $0.64 \pm 0.44(\mathrm{SD} ; n=153)$. In $9 \%$ of the patches, the ratio is greater than 1 . Such patches represent large $I_{\mathrm{A}}$ current "hot spots." In some patches, the $I_{\mathrm{A}}$ current density was too low to measure even though current densities as great as $0.4 \mathrm{pA} / \mu \mathrm{m}^{2}$ were recorded in adjacent patches of similar area and large $I_{\mathrm{A}}$ currents were observed in the whole-cell record. The fact that the average ratio of patch to whole-cell current density is only 0.64 indicates that the axon hillock or initial axon has a higher $I_{\mathrm{A}}$ current density than the soma. In a small sample of 4 patch recordings from the axon hillock, the average ratio was $1.35 \pm$ 1.01 (SD) which supports this conclusion.

In order to determine if there is a gradient in the distribution of $I_{\mathrm{A}}$ across the soma, the cell body was divided into 4 zones corresponding to the soma cap, a point $45^{\circ}$ from the cap that we refer to as $45^{\circ} \mathrm{N}$, the equator of the soma, and a point midway between the equator and the axon hillock at $45^{\circ} \mathrm{S}$. Current densities were determined as before, and the data for patches in each zone were pooled and averaged. The results are shown in Table 1. The average current densities in the 4 zones are not significantly different (2-tailed $t$ test, $p<0.05$ ) and give no indication of an overall gradient in the distribution of $I_{\mathrm{A}}$ channels in the cell body.

The variability in $I_{\mathrm{A}}$ current density between patches on the same cell is illustrated in Figure 3 . In this example, currents were recorded from 3 large patches of similar area (380-430 $\mu \mathrm{m}^{2}$ ) located $20-40 \mu \mathrm{m}$ apart at the soma cap using the same patch pipette. Patch currents were activated by a step to -30 $\mathrm{mV}$ from $-90 \mathrm{mV}$ and scaled by membrane area. The $I_{\mathrm{A}}$ current density varies by a factor of 6.8 between patches in this example.

The wide range of current densities in different patches suggests that $I_{\mathrm{A}}$ channels may occur in clusters. One way to demonstrate this is to group the patch current density data ac- 

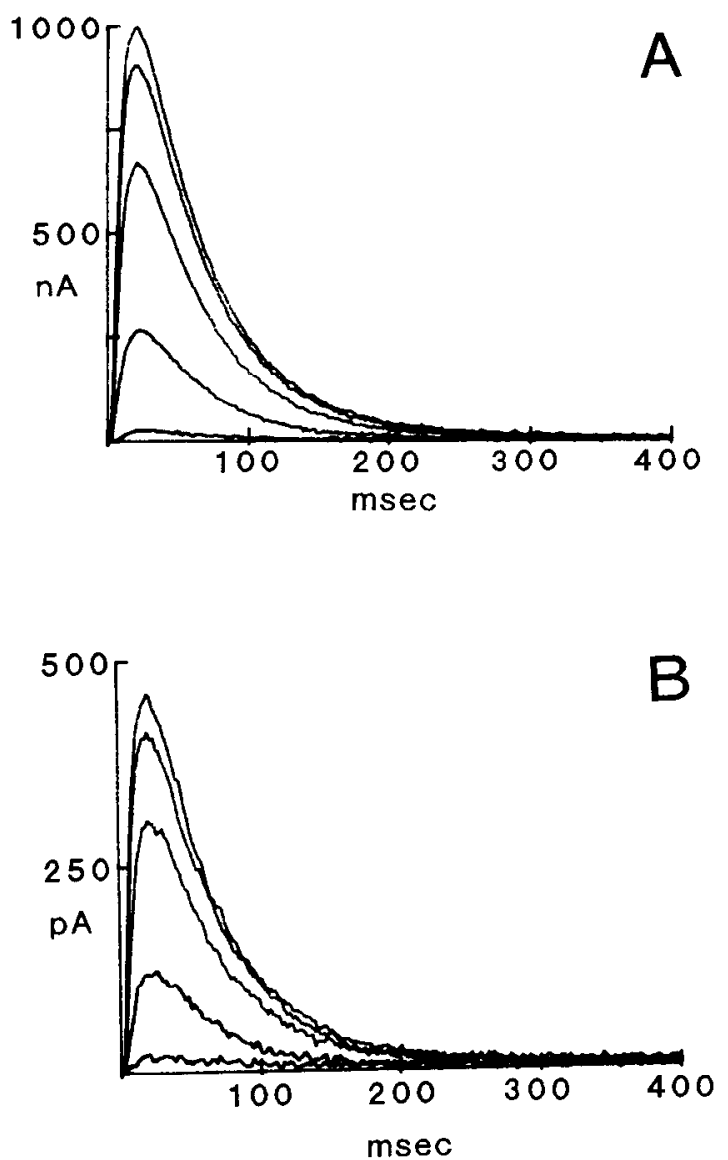

Figure 1. Transient $\mathrm{K}$ currents recorded simultaneously from the entire axotomized cell body $(A)$ and from a large patch at the axon hillock $(B)$. The patch area was $220 \mu \mathrm{m}^{2}$. Currents were activated by depolarizing steps to $-30 \mathrm{mV}$ after $500 \mathrm{msec}$ conditioning steps to voltages between -90 and $-50 \mathrm{mV}$ (increasing in $10 \mathrm{mV}$ increments). Analog filter $f_{c}=2 \mathrm{kHz}$.

cording to the area of the patch and compare the mean and variance of current density between the different area classes. Figure 4 shows that the variance is relatively constant for large patches $\left(>250 \mu \mathrm{m}^{2}\right)$ and increases sharply for smaller patches. This is the expected result if channels are clustered because smaller patches have a greater likelihood of sampling either from a region devoid of channels or from the center of a dense aggregate.

The idea that $I_{\mathrm{A}}$ channels are clustered was analyzed statistically by testing the null hypothesis that the spatial pattern, or dispersion, of channels is random. For a random pattern, the number of active channels per patch, $x_{i}$, in each of $n$ patches of area $A_{i}$, will follow a Poisson distribution with mean density, $\bar{d}$ $=\sum x_{i} / \sum A_{i}$. The variance in channel number between patches, corrected for unequal patch areas, is $s^{2}=\sum\left(x_{i}-d * A_{i}\right)^{2} /(n-$ 1). The overall mean number of channels per patch is $\bar{x}=$ $\sum x_{i} / n$. Since the mean and variance of a discrete Poisson distribution are equal, the sample variance-to-mean ratio, $s^{2} / \bar{x}$ provides a useful measure of spatial randomness. This ratio has been termed either the "index of dispersion" (Darwin, 1957; Selby, 1968; Stitler and Patil, 1969; Ripley, 1981), or "coefficient of dispersion" (Sokal and Rohlf, 1981). For a Poisson distribution the coefficient of dispersion (CD) will be close to 1. Significantly larger values suggest aggregation in the under-

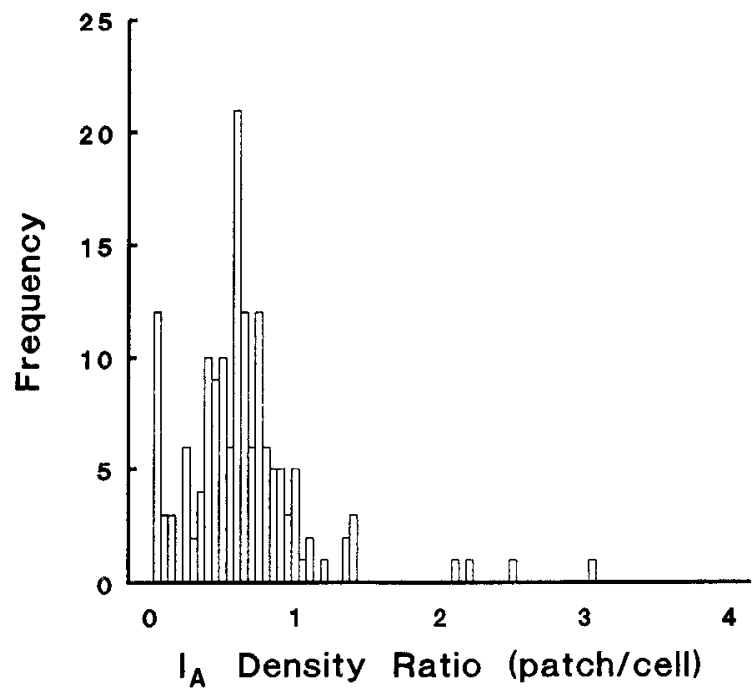

Figure 2. Ratio of $I_{\mathrm{A}}$ current density in somatic patches to the wholecell current density. Whole-cell and patch currents were recorded simultaneously during steps to $-20 \mathrm{mV}$ after a $500 \mathrm{msec}$ conditioning step to $-90 \mathrm{mV}$. Peak currents during the test step were normalized by membrane area. The ratio of $I_{\mathrm{A}}$ current density in the patch to the current density in the entire axotomized cell body was used to construct the histogram (153 patches on 47 neurons are represented).

lying pattern, and smaller values suggest regularity. Because the $\mathrm{CD}$ is essentially a comparison of observed and expected frequencies, the value of $C D *(n-1)$ is approximately distributed as a $X^{2}$ variate with $n-1$ degrees of freedom (Pielou, 1977; Diggle, 1979). Therefore, the probability of any $C D$ value can be obtained from a table of the $X^{2}$ probability distribution.

Experimentally, the power of the $C D$ as a measure of clustering is maximized when all samples (patches) are taken from the same cell, the samples are similar in area, and the number of samples is large. We chose for analysis an experiment in which the $I_{\mathrm{A}}$ channel density had been measured in 30 patches, between 61 and $250 \mu \mathrm{m}^{2}$ in area, at the soma cap of the same neuron. The number of $I_{\mathrm{A}}$ channels activated in each patch during a step from -90 to $-20 \mathrm{mV}$ was estimated by dividing the peak current by the amplitude of the single-channel current at -20 $\mathrm{mV}$ ( $0.43 \mathrm{pA}$, see Fig. 9). Figure 5 shows the channel density in each patch as a function of patch area, and the dotted line indicates the mean channel density for all patches $\left(0.20 / \mu \mathrm{m}^{2}\right)$. The number of channels in different patches is variable, and the variability increases as patch size decreases. The interpatch variance in channel number was 192, and the mean number of channels per patch was 24 . The value of the coefficient of dispersion was 8.1 with 29 degrees of freedom $\left[p\left(X^{2}=234.9\right)<\right.$ 0.001 ], rejecting the null hypothesis of random spatial pattern, and indicating a high degree of clustering in the distribution of

Table 1. $I_{A}$ distribution in 4 regions of the soma

\begin{tabular}{lcccc} 
& \multicolumn{4}{l}{ Current density $\left(\mathrm{pA} / \mu \mathrm{m}^{2}\right)$} \\
\cline { 2 - 5 } & CAP & $45^{\circ} \mathrm{N}$ & EQ & $45^{\circ} \mathrm{S}$ \\
\hline Average & 0.13 & 0.12 & 0.10 & 0.12 \\
SD & 0.19 & 0.13 & 0.74 & 0.12 \\
$n$ & 82 & 32 & 16 & 14 \\
\hline
\end{tabular}




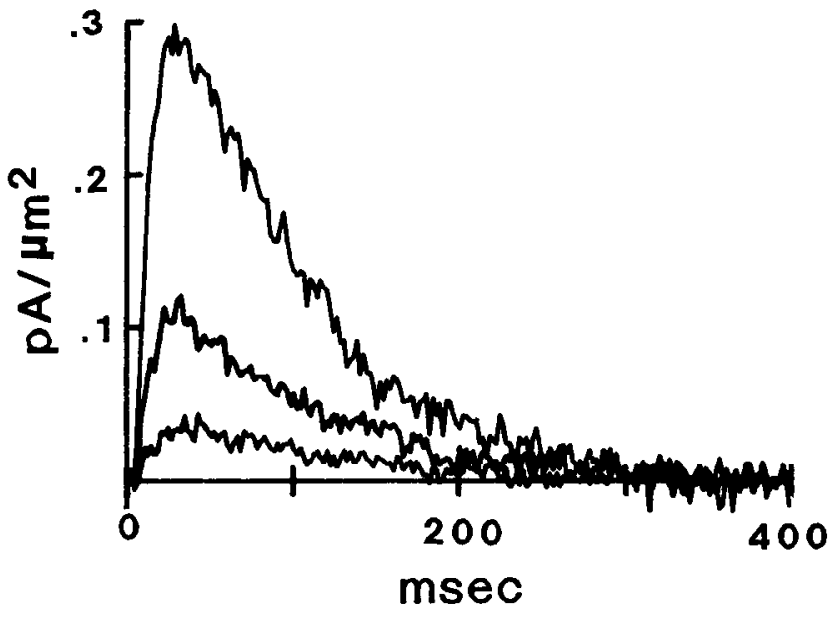

Figure 3. Variability in $I_{\mathrm{A}}$ density in 3 adjacent patches on the same neuron. The peak current during steps to $-30 \mathrm{mV}$ from a conditioning voltage of $-90 \mathrm{mV}$ was divided by patch capacitance to calculate current density. The patch areas were between 380 and $430 \mu \mathrm{m}^{2}$ and their centers were located $20-40 \mu \mathrm{m}$ apart.

$I_{\mathrm{A}}$ channels. This value from 30 patches on a single cell is consistent with CD values of 3.5-24.6 measured in 5 other cells, where between 6 and 11 patches per cell were obtained.

The significance of the above result was also tested empirically using a Monte Carlo simulation to analyze different spatial distributions of channels (B. A. Premack and S. Thompson, unpublished observations). Circular samples were taken from a representative graphical simulation of random channel patterns, using sample areas, number of samples, and mean density identical to those in the data set. The mean $\mathrm{CD}$ for the truly random patterns was 1.1 (range, $0.5-1.7 ; 50$ repeat trials of 30 "patches" each). Clustered patterns (random circular, random ellipsoid, random Gaussian, and negative binomial) were also graphically simulated, and yielded calculated $C D$ values significantly greater

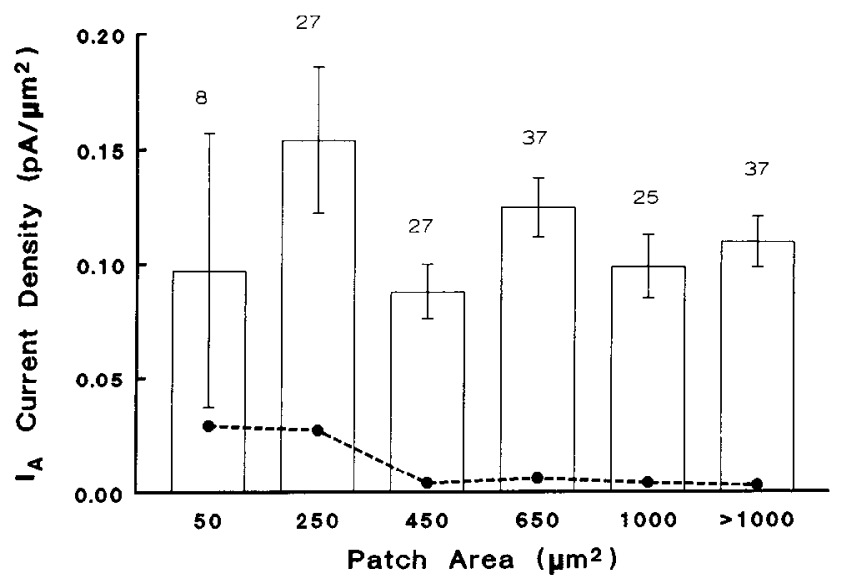

Figure 4. Mean amplitude, SEM, and variance of $I_{\mathrm{A}}$ current density as a function of patch area. Data from large patch and gigaseal patch experiments were grouped by patch area. The gigaseal patch data fall in the $0-50 \mu \mathrm{m}^{2}$ bin. The mean current density and variance were calculated for each bin, and the error bars indicate the SEM (number of patches is specified above error bars). The variance between patches (circles and dotted line) increases sharply for patches less than $250 \mu \mathrm{m}^{2}$ in area. (Note: the axis numbers refer to the upper limit of area in each bin, for example, bin 1 is $0-50 \mu \mathrm{m}^{2}$, bin 2 is $51-250 \mu \mathrm{m}^{2}$.)

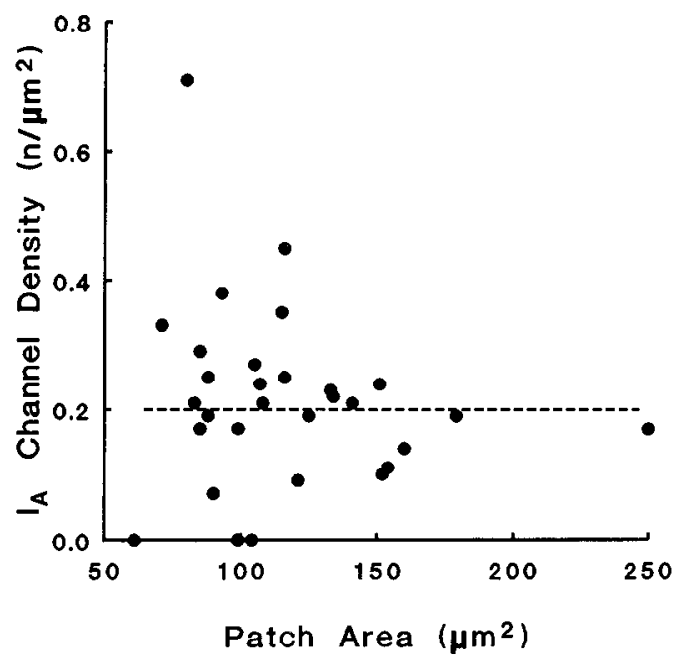

Figure 5. $\quad I_{\mathrm{A}}$ channel density as a function of patch area for 30 patches on the soma cap of the same neuron. Channel density was calculated by dividing the peak current during a step to $-20 \mathrm{mV}$ by the singlechannel current at the same voltage $(0.43 \mathrm{pA})$. The dotted line shows the mean channel density for all patches $\left(0.20 / \mu \mathrm{m}^{2}\right)$. The variance increases as the area of the patch decreases.

than 1 in all trials. Samples obtained from fields of circular or 2-dimensional Gaussian "channel clusters" with areas of 150 $250 \mu \mathrm{m}^{2}$ yielded CDs in the range of 4.3-21.0, values similar to those calculated for the actual data sets. This analysis indicates that $I_{\mathrm{A}}$ channels occur in clusters in the soma but does not require that actual channel clusters have the assumed form. The actual shape of channel clusters has not been determined empirically.

$I_{\mathrm{A}}$ channels were studied on a finer spatial scale using small patch pipettes in the cell-attached configuration after the formation of a gigaseal. $I_{\mathrm{A}}$ channels were identified using 3 criteria that reflect the properties of $I_{\mathrm{A}}$ in whole-cell recordings: (1) $I_{\mathrm{A}}$ channels require a hyperpolarizing prepulse to $-100 \mathrm{mV}$ to fully remove inactivation, (2) the probability of channel opening peaks within a few milliseconds at voltages just positive to the resting potential and then declines rapidly as inactivation occurs, and (3) $I_{\mathrm{A}}$ channels are $\mathrm{K}$ selective and not blocked by external TEA (Thompson, 1977).

There were 2 classes of results in the gigaseal patch experiments. Patches were found to have either no $I_{\mathrm{A}}$ channels or they contained multiple channels so that the current was macroscopic in nature. This is shown for 2 patches of similar area (about 13 $\mu \mathrm{m}^{2}$ ) located $10 \mu \mathrm{m}$ apart on the same cell in Figure 6. At least 17 channels were activated by a step to $0 \mathrm{mV}$ in one patch, while none were activated during the same step in the other. $I_{\mathrm{A}}$ channels were absent in more than $50 \%$ of the gigaseal patch experiments, although in many cases adjacent patches contained multiple channels. The variance in current density between patches in the gigaseal experiments was similar to that observed in the smallest patches studied with large pipettes (see Fig. 4). Since 2 completely different current recording and capacitance measuring systems were used in generating these data, this finding lends support to the idea that the variability in channel density increases as the area of the patch decreases.

In patches containing a high density of $I_{\mathrm{A}}$ channels, we rarely observed channel openings attributable to any of the other types of $\mathrm{K}$ channels that are known to be expressed by these neurons, 


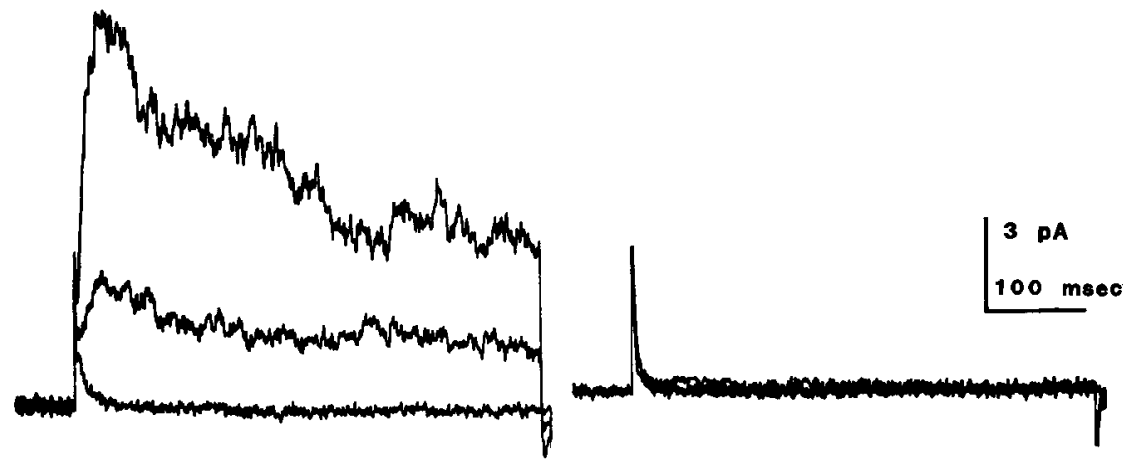

Figure 6. Variability in $I_{\mathrm{A}}$ density in 2 gigaseal patches located $10 \mu \mathrm{m}^{2}$ apart on the soma cap of the same cell. The patch areas $\left(13 \mu \mathrm{m}^{2}\right)$ and seal resistances (120 and $150 \mathrm{G} \Omega$ ) are similar in the 2 recordings. Three activating steps are shown, to $-40,-20$, and $0 \mathrm{mV}$, following $500 \mathrm{msec}$ prepulses to -100 $\mathrm{mV} . I_{\mathrm{A}}$ inactivation is slow in this cell, but the voltage dependence of removal of inactivation (not shown) confirms that the patch contains only $I_{\mathrm{A}}$ channels. Analog filter $f_{c}=1 \mathrm{kHz}$. even though single-channel currents due to the activation of delayed $\mathrm{K}$ currents or $\mathrm{Ca}$-activated $\mathrm{K}$ currents could be easily discerned because of differences in unit conductance. This finding held true for depolarizations up to $+40 \mathrm{mV}$ in the absence of TEA (Fig. 7) where the opening probability for delayed $\mathrm{K}$ channels and $\mathrm{Ca}$-dependent $\mathrm{K}$ channels is high. The results suggest that $I_{\mathrm{A}}$ channels can occur in homogeneous assemblages that are nearly devoid of other $\mathrm{K}$ channel types.

We did not succeed in recording from patches containing only a single $I_{\mathrm{A}}$ channel, but in several experiments the number of channels was small and single-channel openings could be discerned late in the activating pulse. An example from a patch containing a minimum of $5 I_{\mathrm{A}}$ channels is shown in Figure 8. The records in the left panel show patch currents during 4 steps to $0 \mathrm{mV}$ following a $500 \mathrm{msec}$ prepulse to $-80 \mathrm{mV}$ and the ensemble average of 10 consecutive sweeps. There is a high probability of channel opening early in the step, but the probability declines rapidly over the first $50-100 \mathrm{msec}$. The right panel shows steps to $0 \mathrm{mV}$ from the resting potential $(-40 \mathrm{mV})$ and the ensemble average. In the absence of a hyperpolarizing prepulse, no $I_{\mathrm{A}}$ channel openings are observed. The mean unitary current was measured at a number of voltages in order to construct the open channel $I(V)$ curve in Figure $9 A$. Extrapolation of the $I(V)$ curve gives a reversal potential of $-64 \mathrm{mV}$, which is close to the reversal potential for whole cell $I_{\mathrm{A}}$, and the slope of the line fitted to the data indicates a single-channel conductance of about $9 \mathrm{pS}$. Figure $9 B$ shows the amplitude histogram for single-channel currents at one voltage $(0 \mathrm{mV})$. The distribution is unimodal, and the mean amplitude of the single-channel current at $0 \mathrm{mV}$ is $0.6 \mathrm{pA}$. Similar analysis of currents activated by steps to -30 and $-20 \mathrm{mV}$ resulted in mean unitary channel currents of 0.33 and $0.43 \mathrm{pA}$, respectively.

The voltage dependencc of activation and inactivation for $I_{\mathrm{A}}$ in gigaseal patch experiments was similar to that measured in whole cell and large patch experiments. With gigaseal patches we were able to extend the activation curve to more depolarized voltages because we could be sure that other channel types did not contaminate the $I_{\mathrm{A}}$ records. The voltage dependence of activation is plotted in Figure $9 C$ along with the steady-state inactivation curve normalized to the value at $-100 \mathrm{mV}$. Inactivation is about $30 \%$ removed at the resting potential $(-40 \mathrm{mV})$, but spontaneous openings at this voltage were not observed, possibly because the probability of channel opening at the resting potential is very small. The activation curve, plotted as conductance, increases almost linearly above $-40 \mathrm{mV}$ and does not reach saturation by $+60 \mathrm{mV}$.

\section{Cellular variability in $\mathrm{I}_{A}$ amplitude}

Most of the neurons in this study expressed $I_{\mathrm{A}}$, but there were large differences in whole-cell current density. The range of $I_{\mathrm{A}}$ current densities at $-20 \mathrm{mV}$ in whole cell records from 47 pedal and pleural ganglion neurons was between zero and $0.79 \mathrm{pA}$ $\mu \mathrm{m}^{2}$ with a mean value of $0.17 \pm .15 \mathrm{pA} / \mu \mathrm{m}^{2}$ (SD). Some of the variability results from uncertainties in the cell-isolation procedure. The length of axon remaining after axotomy is variable and, for reasons stated above, the average current density over much of the soma is expected to be lower than the current density in the initial axon. The peak current density in wholecell recordings will be higher when the axon remnant is longer, even if the surface area is measured correctly and the cells are

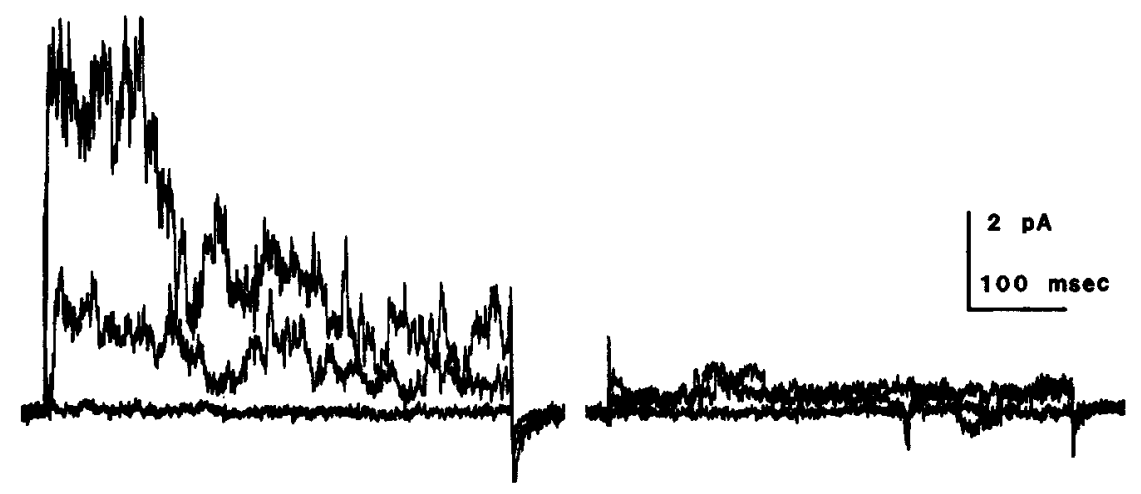

Figure 7. Gigaseal patch containing a high density of $I_{\mathrm{A}}$ channels with little evidence of other $\mathrm{K}$ channel types. Left, Currents activated by depolarizing steps to $-40,0$, and $+40 \mathrm{mV}$, from -100 $\mathrm{mV}$. Right, Currents in the same patch during identical depolarizing steps from a holding voltage of $-40 \mathrm{mV} . I_{\mathrm{A}}$ is absent during depolarization from this holding voltage and other $\mathrm{K}$ channels are not activated, suggesting that the patch contained almost entirely $I_{\mathrm{A}}$ channels. The channel opening seen during the step to $+40 \mathrm{mV}$ from -40 $\mathrm{mV}$ reversed at $0 \mathrm{mV}$, showed little voltage dependence, and appeared to be a nonselective cation channel or $\mathrm{Cl}$ channel. Analog filter $f_{c}=1 \mathrm{kHz}$. 
Figure 8. Unitary currents in a gigaseal attached patch with few active $I_{\mathrm{A}}$ channels. Left, The 4 upper traces show currents during depolarizing steps to 0 from $-80 \mathrm{mV}$. The ffth trace shows the ensemble average of 10 consecutive sweeps. Unitary channel openings late in the activating pulse have an amplitude of about $0.6 \mathrm{pA}$. Right, Sweeps to $0 \mathrm{mV}$ from the resting potential, -40 $\mathrm{mV}$. No openings are observed. The pipette contained $100 \mathrm{~mm}$ TEA in ASW which confirms that the currents in the left panel result from the activation of $I_{\mathrm{A}}$ channels. Analog filter $f_{c}=1 \mathrm{kHz}$; digital filter $f_{c}=500 \mathrm{~Hz}$.

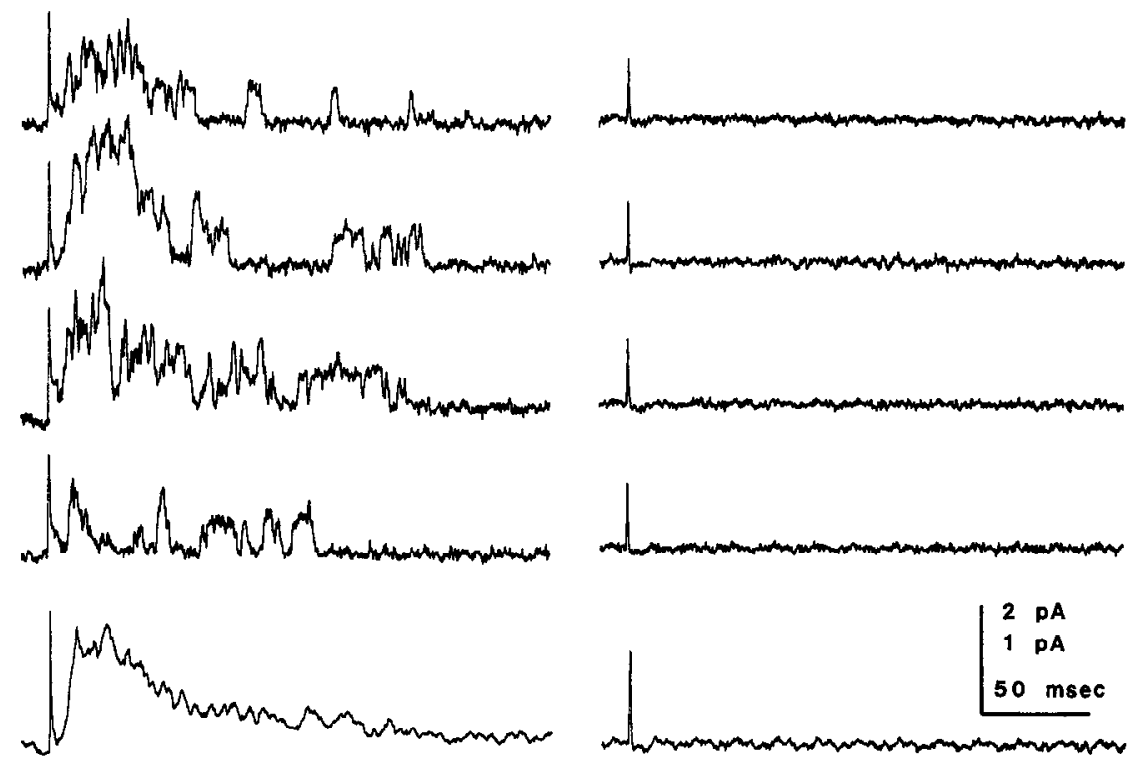

identical in other respects. The axotomy procedure was performed in a uniform way, however, and it is unlikely that differences in the length of attached axon can explain the range of current densities observed. It is reasonable to conclude that individual neurons differ in overall $I_{\mathrm{A}}$ current density. Serrano (1982) studied neurons in the same species that were rigorously identified and reached a similar conclusion. Serrano's results and ours suggest that the $I_{\mathrm{A}}$ current density is actively regulated and that the set point for regulation differs characteristically between neurons. Just how strict the regulation is cannot be assessed at present, however, because $I_{\mathrm{A}}$ channels are not uniformly distributed between the soma and axon and because of uncertainties in the length of axon remaining after cell isolation.

\section{Cellular variability in the kinetics of $\mathrm{I}_{A}$}

There is a great deal of variability in the rate of $I_{\mathrm{A}}$ inactivation during depolarizing steps in different cells. This was reported by Connor and Stevens (1971) and Neher (1971) and studied in detail by Seranno (1982). In the present study, the inactivation of whole-cell $I_{\mathrm{A}}$ during a depolarizing step always followed an exponential time course, but the time constant varied between 25 and $560 \mathrm{msec}$ in different cells. The insert in Figure 10 shows $I_{\mathrm{A}}$ during steps to $-30 \mathrm{mV}$ from a holding voltage of $-90 \mathrm{mV}$ in 4 neurons isolated from the pedal and pleural ganglia of Doriopsilla. The currents are scaled to the same peak amplitude so that their time courses can be easily compared. The time to peak, and especially the inactivation rate, differs between cells and in these examples the time constant of inactivation ranged from 59 to $127 \mathrm{msec}$. A histogram showing the distribution of inactivation time constants of whole-cell currents in 131 experiments on pedal and pleural neurons is shown in Figure 10. The currents were activated by a step to $-30 \mathrm{mV}$ from a conditioning voltage of $-90 \mathrm{mV}$, and inactivation time constants were estimated by measuring the time to fall to $1 / e$ of the peak
A

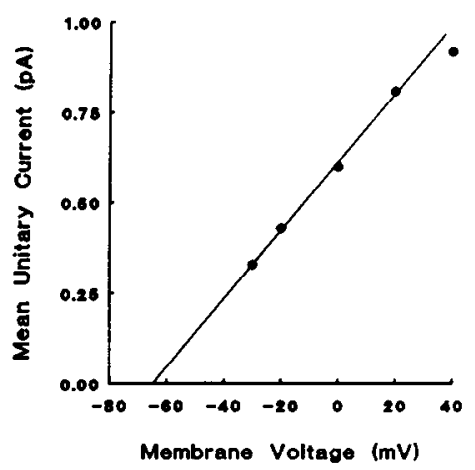

B

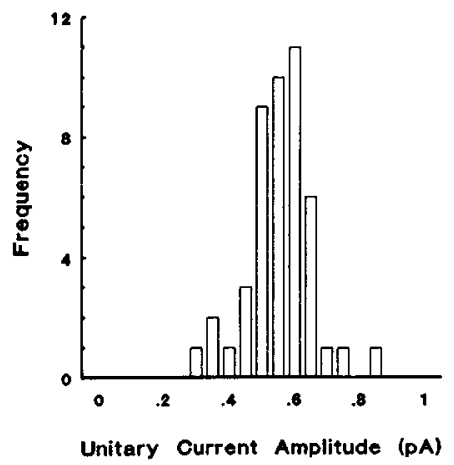

C

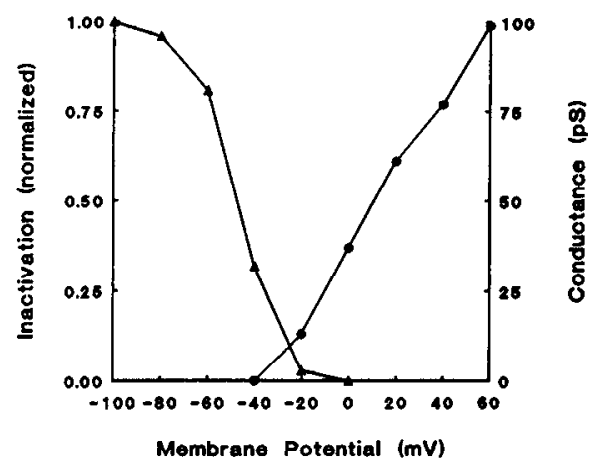

Figure 9. Properties of $I_{\mathrm{A}}$ channels in an attached gigaseal patch containing a minimum of 13 channels. $A$, Open channel $I(V)$ curve. The data points represent the mean unitary current based on samples of 24-85 openings at each test voltage. The linear regression gives an extrapolated reversal potential of $-64 \mathrm{mV}$, and a slope conductance of approximately $9 \mathrm{pS}$. The recording pipette contained normal ASW. At the most positive voltage the single-channel currents show evidence of rectification. $B$, Amplitude histogram for unitary currents at $0 \mathrm{mV}$. The distribution peaks at $0.6 \mathrm{pA}$ and is approximately Gaussian. $C$, Voltage dependence of $I_{\mathrm{A}}$ gating parameters. The inactivation variable is normalized to the value at $-100 \mathrm{mV}$. The activation curve is not normalized and shows the peak conductance value at each voltage. 


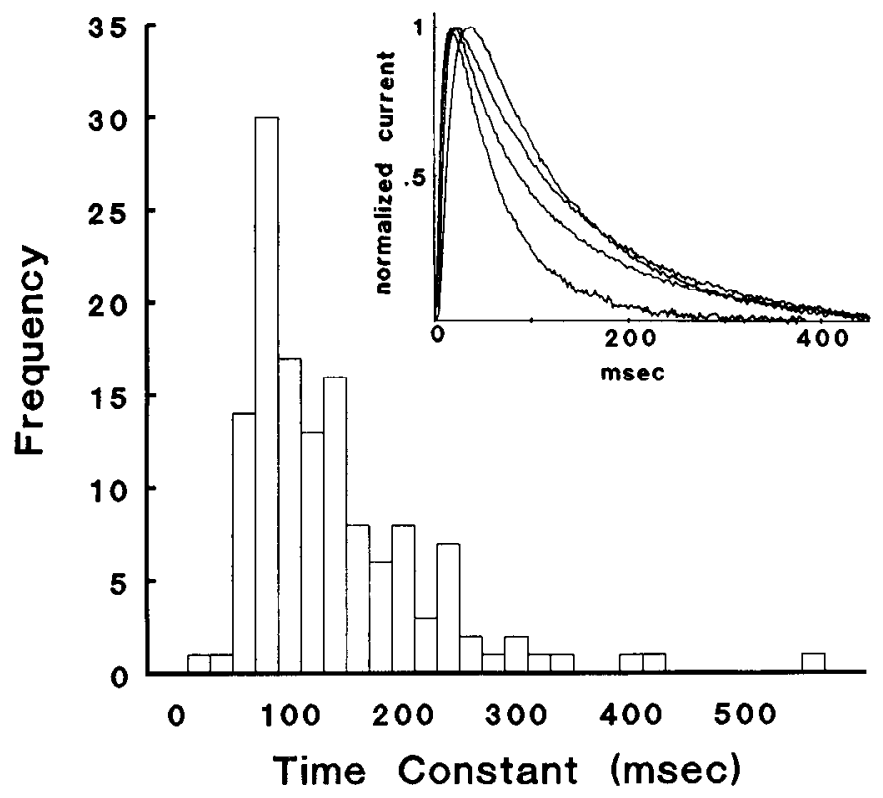

Figure 10. Histogram showing the distribution of inactivation time constants measured in whole-cell voltage-clamp experiments on 131 neurons. In each case, $I_{\mathrm{A}}$ was activated by a step from -90 or -100 $\mathrm{mV}$ to $-30 \mathrm{mV}$ and the time constant of inactivation at $-30 \mathrm{mV}$ was estimated from the time to fall to $1 / e$ times the peak amplitude. The mean time constant was $147 \pm 80(\mathrm{SD}) \mathrm{msec}$. The range was $25-560$ msec. Inset, Whole-cell $I_{\mathrm{A}}$ recorded from 4 different Doriopsilla neurons. Currents were activated by steps to $-30 \mathrm{mV}$ after a $500 \mathrm{msec}$ condition pulse to $-90 \mathrm{mV}$ and scaled by peak amplitude. The inactivation time constants for the 4 cells are $59,96,112$, and $127 \mathrm{msec}$.

amplitude. The distribution is broad, has a single peak, and is skewed toward the longer time constants.

Cellular variability in $I_{\mathrm{A}}$ inactivation rate does not result from differences in the voltage dependence of rate constants associated with inactivation. Connor and Stevens (1971) showed that the rate of $I_{\mathrm{A}}$ inactivation in these cells is nearly independent of voltage in the range used in these experiments, and the present results support that conclusion. In addition, there is little cellular variability in the steady-state voltage dependence of $I_{\mathrm{A}}$ activation or inactivation, and no systematic difference in current reversal potential (see also Serrano, 1982).

\section{Comparison of inactivation rates between patches on the same} cell

One possible explanation for cellular variability in $I_{\mathrm{A}}$ inactivation is that the whole-cell current in each neuron may result from a mixture of $I_{\mathrm{A}}$ channel types, each type having a different inactivation rate. This idea can be tested by comparing the time constant of $I_{\mathrm{A}}$ inactivation in multiple patches on the same cell. Figure 11 shows the whole-cell current and currents in 8 different patches during a standard activating pulse. All of the patch currents inactivate over approximately the same time coursc as the whole-cell current. This finding was characteristic of virtually every experiment; there was only one patch, in more than 200 , in which the rate of inactivation was distinctly different from the whole-cell inactivation rate.

Macroscopic currents recorded with large patch electrodes result from the activation of hundreds of $I_{\mathrm{A}}$ channels, and it would be difficult to detect channels with different kinetics if they occur rarely. One way to address this sampling problem is

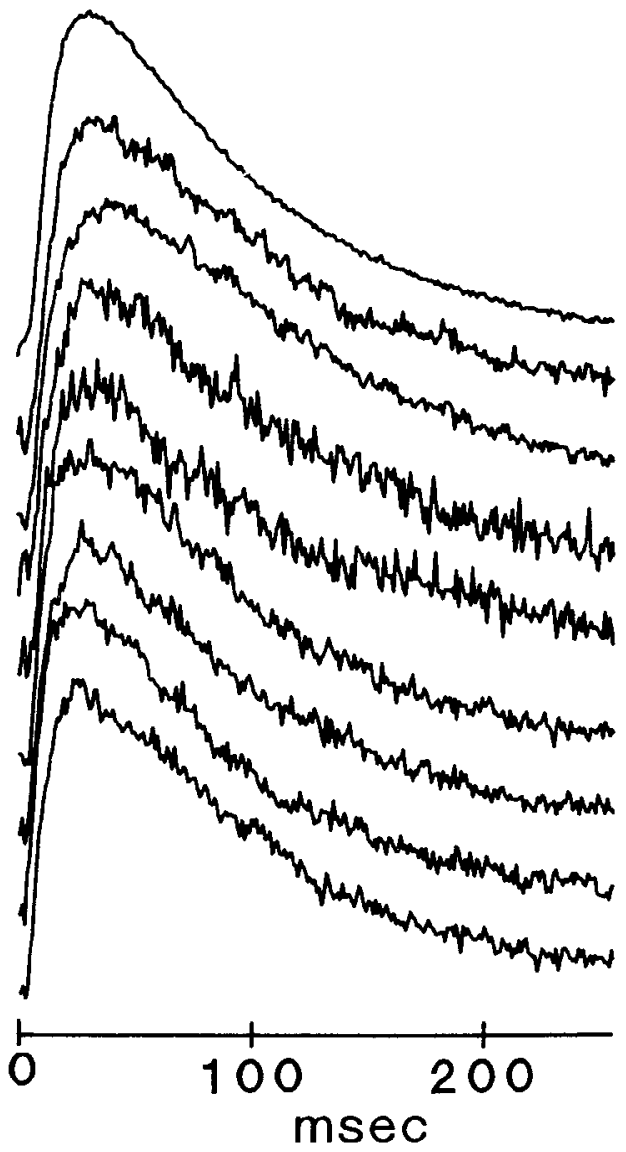

Figure 11. Comparison of $I_{\mathrm{A}}$ inactivation kinetics in multiple patches on the same neuron. The whole-cell current (top trace) and currents from 8 patches on the same cell are shown in this raster plot. The currents are aligned to the time of the step from -90 to $-30 \mathrm{mV}$, and the traces are displaced downward so that the time courses of the individual currents can be compared. The patches were between 625 and $875 \mu \mathrm{m}^{2}$ in area, and the patch-current densities ranged from 0.09 to $0.21 \mathrm{pA} / \mu \mathrm{m}^{2}$. The time constant of $I_{\mathrm{A}}$ inactivation in the whole-cell record was 121 msec.

to record currents from multiple patches on the same neuron using a range of patch pipette diameters and then compare the time constants of inactivation in patches of different area. If inactivation continues to follow a single-exponential time course, and the time constant remains the same, as the area of the patch and the number of channels/patch decreases, we would conclude that a single type of $I_{\mathrm{A}}$ channel predominates. If, however, the time constants diverge, or if inactivation deviates from a single exponential, as patch area decreases we would conclude that more than one kinetically distinct type of $I_{\mathrm{A}}$ channel is expressed by the cell. Figure 12 illustrates an experiment in which $I_{\mathrm{A}}$ was recorded from 9 patches on a single neuron using 3 patch pipettes with different tip diameters. The time constant of $I_{\mathrm{A}}$ inactivation during a standard test depolarization was determined by fitting exponentials to the inactivating phase of each current using a least-squares algorithm. In all cases, inactivation is best fit by a single-exponential relaxation; attempts to fit the data with the product of 2 exponentials did not increase the accuracy. The time constant of inactivation for the whole-cell current was 71 msec, which is near the low end of the distribution for the population of cells in the study. The areas of the patches range from 50 to $3750 \mu \mathrm{m}^{2}$, and between 12 and $2420 I_{\mathrm{A}}$ channels 
Figure 12. $I_{\mathrm{A}}$ currents recorded from 9 patches on the same cell. Three patch pipettes with different tip diameters were used in order to record from patches ranging from 50 to $3750 \mu \mathrm{m}^{2}$ in area. Currents were recorded during a step to -30 from a conditioning voltage of -90 $\mathrm{mV}$ in each patch. The peak current during the step was between 3.9 and $800 \mathrm{pA}$ in different patches, which corresponds to the activation of between 12 and 2420 channels. For each patch record, the time constant of inactivation was determined by fitting a single exponential to the inactivating phase of the current using the method of least squares. Inset, Time constant of inactivation as a function of patch area. The time constant of inactivation in the whole cell $(71 \mathrm{msec})$ is shown by the solid horizontal line. The average time constant for the patch currents was 70.1 $\pm 6.5(\mathrm{SD}) \mathrm{msec}$.

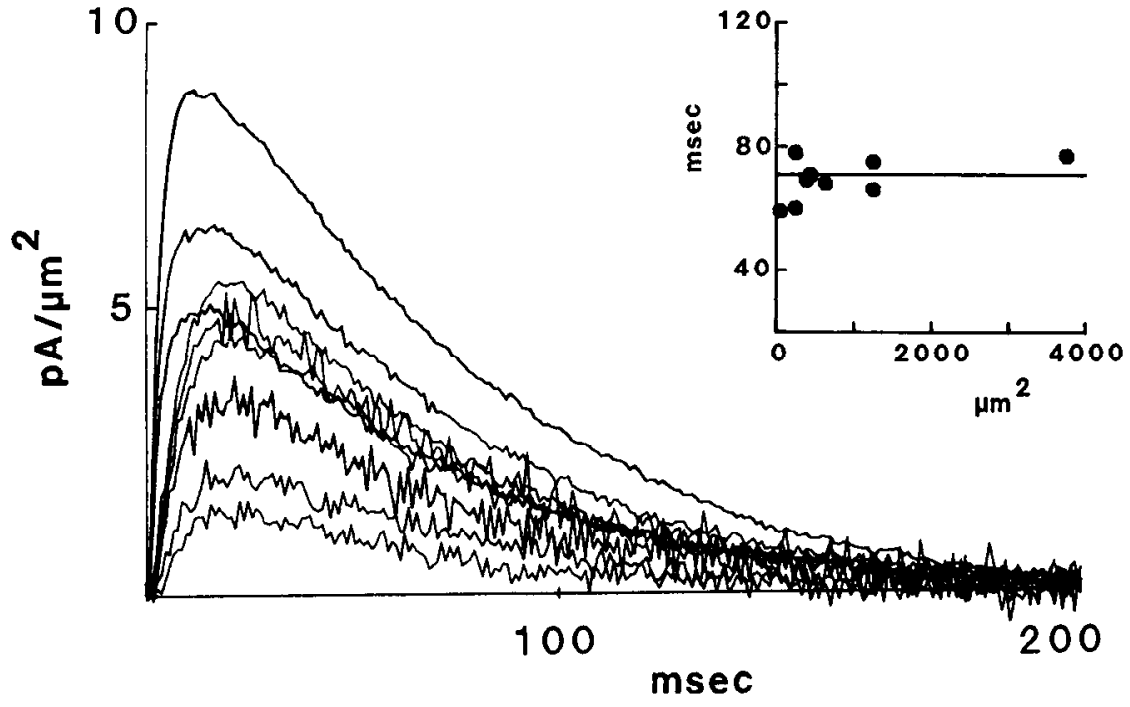

were activated at the peak of the current in different patches. The mean inactivation time constant for the 9 patches was 70 $\pm 6.5 \mathrm{msec}(\mathrm{SD})$ and the range was $59-77 \mathrm{msec}$. The time constants for the various patches are not statistically different $(t$ test, $p<0.05$ ). Much of the variability in this experiment results from difficulties encountered in fitting exponentials to noisy data, but it is clear that the distribution of inactivation time constants for multiple patches on a single neuron is very much narrower than the distribution of time constants for wholecell currents in the sample of 131 neurons (Fig. 10). In 5 repeat experiments in which between 7 and 12 patches were studied on the same cell, the inactivation time constants for the patch currents were not significantly different than the mean time constant of whole-cell current. These results can be interpreted in 2 ways: Either, (1) individual neurons express predominantly a single type of $I_{\mathrm{A}}$ channel, or (2) all patches on the same cell contain the same mixture of several channel types with none predominating.

\section{Discussion}

Transient potassium currents similar to $I_{\mathrm{A}}$ are found in many neuronal and muscle preparations (Rudy, 1988) and play an important role in regulating excitability because they begin to activate at subthreshold voltages where the total conductance of the membrane is low. As a result, $I_{\mathrm{A}}$ influences both the approach to threshold at the onset of a stimulus and the repetitive firing rate (Connor and Stevens, 1971; Connor, 1978). In molluscan neurons, action potentials are initiated in the proximal axon rather than the soma (Tauc, 1962; Johnson and Thompson, 1989), and yet $I_{\mathrm{A}}$ occurs in the soma where it may reach a higher density than the inward $\mathrm{Na}$ and $\mathrm{Ca}$ currents (Thompson and Coombs, 1988; Johnson and Thompson, 1989). The electrotonic length of large molluscan neurons is reported to be $6-16 \mathrm{~mm}$ in the steady state, which means that the spikeinitiating zone is electrically close to the cell body (Graubard, 1975). The activation of somatic $I_{\mathrm{A}}$ channels, therefore, is expected to influence spike initiation in the proximal axon, but the particular spatial distribution of $I_{\mathrm{A}}$ channels in the soma will have no direct effect on spike initiation because the soma is usually isopotential.

\section{Spatial distribution of $\mathrm{I}_{A}$ in the soma}

The average $I_{\mathrm{A}}$ current density is approximately the same across the cell body surface, and there is no evidence that the current is distributed in a gradient. This contrasts with the results of experiments on somatic $\mathrm{Ca}$ and $\mathrm{Na}$ currents in molluscan neurons where the current density was found to increase from a low near the soma cap to a high near the emergence of the axon (Kado, 1973; Thompson and Coombs, 1988). The average ratio of patch-current density to whole-cell current density was only 0.64 , however, indicating that some other region of the axotomized cell has a higher concentration of $I_{\mathrm{A}}$ channels than much of the cell body. The region of higher current density might include the base of the soma and axon hillock, or the initial segment of the axon that remains after axotomy. Patches from the axon hillock also suggest that there is a high density of $I_{\mathrm{A}}$ channels near the site of spike initiation.

On a finer scale, the distribution of $I_{\mathrm{A}}$ in the soma is clearly not uniform. Patches of nearly equal area may have widely different current densities. When the current density data from a large number of cells were grouped by patch area, it was seen that the variance increased sharply below about $250 \mu \mathrm{m}^{2}$. The increase in variance results from a greater number of very low and very high density patches which is the expected result when the patch area begins to converge on either the cluster arca or the intercluster space. The results suggest that the upper limit for the area of $I_{\mathrm{A}}$ channel clusters is about $250 \mu \mathrm{m}^{2}$. The large values obtained for the coefficient of dispersion strongly support the idea that $I_{\mathrm{A}}$ channels occur in clusters. The Monte Carlo simulation we used tested a variety of cluster shapes and yielded $\mathrm{CD}$ values similar to that of the actual data set for circular clusters with areas of $150-250 \mu \mathrm{m}^{2}$. Furthermore, the data in Figure 3 showed that the current-density changes by a factor greater than 6 when a relatively large patch pipette (patch area about $400 \mu \mathrm{m}^{2}$ ) is displaced $30-40 \mu \mathrm{m}$ along the surface. All of these results are consistent with a maximum cluster size of roughly $250 \mu \mathrm{m}^{2}$. This is about the same as the area of $\mathrm{Na}$ channel aggregates away from the endplate on frog skeletal muscle cells, where the current density varies by a factor of 3 over $10-30 \mu \mathrm{m}$ (Almers et al., 1983). It is apparent that ion channels 
occur in large clusters in a number of preparations and that channel aggregation may reflect a general principle of membrane organization (see Almers and Stirling, 1984; Poo, 1985; Angelides et al., 1988). This type of organization implies that mechanisms exist to group channels into clusters and that these mechanisms are persistently active in adult neurons where they continue to produce aggregation during channel turnover.

An estimate can be made of the spacing betwecn channcls within a cluster. If it is assumed that the highest channel density observed in gigaseal patch experiments represents a patch located at the center of a cluster, then the highest density of active channels is about $1 / \mu \mathrm{m}^{2}$ at $-20 \mathrm{mV}$, or about $8 / \mu \mathrm{m}^{2}$ at +60 $\mathrm{mV}$ where the probability of channel opening is greater. Although calculation of channel density by extrapolation from the current peak may underestimate the total channel density, this is still a relatively low number compared with the $\mathrm{Na}$ channel density in the squid axon $\left(166-533 / \mu \mathrm{m}^{2}\right.$; Hille, 1984) or in squid stellate ganglion cell bodies $\left(37 / \mu \mathrm{m}^{2}\right.$; Brismar and Gilly, 1987) calculated by similar methods.

An interesting finding in this study is that gigaseal patches with $I_{\mathrm{A}}$ channels appear to contain very few channels of other types. These neurons produce large delayed outward currents during depolarizing steps. The single-channel currents associatcd with the delayed $K$ current and the Ca-activated $K$ current can be easily distinguished from the $I_{\mathrm{A}}$ single-channel current, and yet openings attributable to these types of channels are not usually seen in patches that contain $I_{\mathrm{A}}$ channels. There are several possible explanations for this observation: (1) the other types of $\mathrm{K}$ channels may be excluded from $I_{\mathrm{A}}$ channel clusters, possibly because $I_{\mathrm{A}}$ channels have a mutual affinity that is not shared with other channels so that they tend to group together in a manner similar to that described for $\mathrm{ACh}$ receptors on myoballs (Poo, 1985); (2) another possibility is that the mechanism responsible for anchoring $I_{\mathrm{A}}$ channels to cytoskeletal or extracellular structures is specific and does not recognize other $\mathrm{K}$ channel types. In either case, the data suggest that a selective trapping process results in the formation of isochannel $I_{\mathrm{A}}$ aggregates.

\section{Variability in $\mathrm{I}_{A}$ kinetics}

The kinetics of $I_{\mathrm{A}}$, especially the rate of inactivation during depolarization, differ between cells, and there are several possible mechanisms for generating this diversity. One possibility is that several genes encode transient $K$ channels with different kinetic properties. Experiments on Drosophila behavioral mutants have shown that mutations at the Shaker locus affect A-type currents in muscle cells and myocytes (Salkoff and Wyman, 1981a, b; Wu et al., 1983, 1985) but do not affect the transient $\mathrm{K}$ current in neurons (Solc et al., 1987). The neuronal current (A2) and the muscle current (A1) in Drosophila have distinctly different properties, including differences in voltage dependence and kinetics of inactivation, and it is clear that they result from the expression of different genes. The Drosophila experiments document the fact that multiple genea for transient $\mathrm{K}$ channels can exist in the same organism and that they can be expressed differentially in different cell types.

Type A2 currents in Drosophila resemble $I_{\mathrm{A}}$ molluscan neurons in voltage dependence of activation and inactivation, relatively slow inactivation rate, inactivation to completion during depolarizing steps, and relative insensitivity of the inactivation rate to voltage. The 2 currents differ in one respect: the time course of inactivation of $\mathrm{A} 2$ current is characterized by the sum of 2 exponentials, while the current in molluscan neurons inactivates over a single-exponential time course. The single-channel conductance of A2 channels is 5-8 pS (Solc et al., 1987), which is similar to the value obtained in this study ( $9 \mathrm{pS})$, although salines of different ionic strength were used in the 2 studies. Taylor (1987) reported a single-channel conductance for $I_{\mathrm{A}}$ channels in Helix neurons of $14 \mathrm{pS}$. The transient $\mathrm{K}$ current in Drosophila muscle cells and myocytes (type A1) has a single-channel conductance of $14 \mathrm{pS}$ but is unlike the molluscan current in that it activates at more depolarized voltages (Zagotta et al., 1988).

A second mechanism for generating diversity in channel properties might involve alternative splicing of a single gene. Several groups have prepared cDNA clones from the Shaker gene, and it was found that the cDNAs are highly variable at their $5^{\prime}$ and 3' ends (Baumann et al., 1987; Kamb et al., 1987; Tempel et al., 1987; Kamb et al., 1988; Schwarz et al., 1988). This variability appears to result from alternative splicing of the large Shaker transcript, producing several different classes of mRNAs (Tempel et al., 1987; Kamb et al., 1988; Schwarz et al., 1988). Kamb et al. (1988) examined the structure of the Shaker gene and concluded that there may be as many as 24 possible transcripts. Timpe et al. (1988) studied transient K currents expressed in Xenopus oocytes after injecting 2 different Shaker mRNAs and found that they resulted in transient currents with different kinetic properties. This clearly shows that alternative splicing can generate a number of different channel types. It is not known how many channel types can arise in this way in Drosophila, but because the channels may normally exist as heteromultimers and at least 4 distinct channel proteins are encoded at the Shaker locus, the number of possibilities is potentially large (Iverson et al., 1989).

A third way to generate diversity in the properties of $I_{\mathrm{A}}$ channels might involve posttranslational modification of the gene products. Strong and Kaczmarek (1986) found that the rate of $I_{\mathrm{A}}$ inactivation in Aplysia bag cell neurons was modified by forskolin, an activator of adenylate cyclase. One interpretation of this finding is that the inactivation rate is changed after phosphorylation of $I_{\mathrm{A}}$ channels by a cAMP-dependent protein kinase. The implication for the present work is that cellular differences in inactivation rate could result from differences in the expression of a kinase or in the level of cytoplasmic cAMP. This mechanism is not likely to apply to the dorid neurons in this study for several reasons. First, the characteristic signature of forskolin's action in Aplysia bag cells and dorid neurons is a change in the time course of $I_{\mathrm{A}}$ inactivation from an exponential relaxation to onc that is better characterized by the product of 2 exponentials (Strong, 1984; Strong and Kaczmarek, 1986; Coombs and Thompson, 1987). In the present experiments, the inactivation of both whole-cell and patch currents was best fit by a single exponential in all cases. Second, experiments on dorid neurons and other cells have shown that the effect of forskolin on $I_{\mathrm{A}}$ is not mediated by cAMP but results from a voltage-dependent, anesthetic-like interaction of forskolin with $I_{\mathrm{A}}$ channels (Coombs and Thompson, 1987; Hoshi et al., 1988). While it is unlikely that cAMP-dependent phosphorylation is involved in posttranslational modification of $I_{\mathrm{A}}$ channels in dorid neurons, it is possible that other posttranslational events could be important in modulating the rate of inactivation.

The present experiments do not allow us to choose between these alternatives, but patch recording is helpful at another level. Cellular differences in inactivation rate would occur if individual 
neurons preferentially express only one of several possible $I_{\mathrm{A}}$ channel types. Alternatively, individual cells might express a number of channel types simultaneously. Because the wholecell current results from the activation of a very large number of channels (about $3 \times 10^{6}$ channels for the example in Fig. 1), cellular variability in kinetics could be explained if a number of different types of channels are expressed in different ratios in individual neurons. Patch recording can help decide between these alternatives. The histogram in Figure 10, depicting the inactivation time constants of whole-cell currents in a large number of preparations, is not consistent with the idea that only a limited number of different $I_{\mathrm{A}}$ channel types are available for expression. If there were only a few channel types, we would expect to see multiple peaks in the distribution. Instead, the histogram suggests that there are many channel types.

If each neuron expresses several channel types simultaneously, we would expect to record $I_{\mathrm{A}}$ currents with different inactivation rates when surveying a number of patches on the same neuron. Furthermore, we would expect that inactivation in patches containing small numbers of channels might not follow a single-exponential time course. In all but one example, however, the currents in multiple patches from the same cell inactivated at the same rate as the whole-cell current, even in small patches containing at most a few dozen active channels. Inactivation of patch currents was always exponential. We cannot be certain that alternate channel types do not occur rarely, an uncertainty that results from difficulty in fitting exponential functions to noisy records, but it is clear that the range of inactivation time constants in multiple patches on the same cell is very much less than the range of whole-cell inactivation time constants in different cells. The best approach toward identifying rare channel types would be to compare the amplitudes and kinetic properties of single-channel currents from a number of patches on the same neuron. This was not achieved in the present study because we were unable to record from patches containing only one channel, probably because $I_{\mathrm{A}}$ channels normally occur in clusters.

The results of these experiments strongly suggest that each individual neuron expresses predominantly a single type of $I_{\mathrm{A}}$ channel. Whether the particular channel type results from the expression of a unique channel message, from a specific posttranslational pathway responsible for the final channel phenotype, or is influenced by cellular differences in the lipid environment surrounding $I_{\mathrm{A}}$ channels has yet to be determined.

\section{References}

Adams, D. J., S. J. Smith, and S. H. Thompson (1980) Ionic currents in molluscan soma. Annu. Rev. Neurosci. 3: 141-167.

Almers, W., and C. Stirling (1984) Distribution of transport proteins over animal cell membranes. J. Membr. Biol. 77: 169-186.

Almers, W., P. R. Stanfield, and W. Stuhmer (1983) Lateral distribution of sodium and potassium channels in frog skeletal muscle: Measurements with a patch-clamp technique. J. Physiol. (Lond.) 336: 261-284.

Angelides, K. J., L. W. Elmer, D. Loftus, and E. Elson (1988) Distribution and lateral mobility of voltage-dependent sodium channels in neurons. J. Cell. Biol. 106: 1911-1925.

Baumann, A., I. Krah-Jentgens, R. Mueller, F. Mueller-Holtkamp, R. Seidel, N. Kecskemethy, J. Casal, A. Ferrus, and O. Pongs (1987) Molecular organization of the maternal effect region of the Shaker complex of Drosophila: Characterization of an $\mathrm{I}_{\mathrm{A}}$ channel transcript with homology to vertebrate $\mathrm{Na}^{+}$channel. EMBO J. 6: 3419-3429.

Bevington, P. R. (1969) Data Reduction and Error Analysis for the Physical Sciences, McGraw-Hill, New York.
Brismar, T., and W. F. Gilly (1987) Synthesis of sodium channels in the cell bodies of squid giant axons. Proc. Natl. Acad. Sci. USA 84 1459-1463.

Connor, J. A. (1978) Slow repetitive activity from fast conductance changes in neurons. Fed. Proc. 37: 2139-2145.

Connor, J. A., and C. F. Stevens (1971) Prediction of repetitive firing behaviour from voltage clamp data on an isolated neurone soma. J. Physiol. (Lond.) 213: 31-53.

Coombs, J., and S. Thompson (1987) Forskolin's effect on transient $\mathrm{K}$ current in nudibranch neurons is not reproduced by cAMP. $\mathrm{J}$. Neurosci. 7: 443-452.

Darwin, J. H. (1957) The power of the index of dispersion. Biometrika 37: 59-73.

Diggle, P. J. (1979) Statistical methods for spatial point patterns in ecology. In Spatial and Temporal Analysis in Ecology, pp. 95-150, R. M. Cormack and J. K. Ord, eds., International Co-operative Publishing House, Fairland, MD.

Graubard, K. (1975) Voltage attenuation within Aplysia neurons: 'The effect of branching pattern. Brain Res. 38: 325-332.

Hille, B. (1984) Ionic Channels of Excitable Membranes, Sinauer Associates, Sunderland, MA.

Hoshi, T., S. S. Garber, and R. W. Aldrich (1988) Effect of forskolin on voltage-gated $\mathrm{K}$ channels is independent of adenylate cyclase activation. Science 240: 1652-1655.

Iverson, L. E., M. A. Tanouye, H. A. Lester, N. Davidson, and B. Rudy (1989) Expression of A-type potassium channels from Shaker cDNAs. Proc. Natl. Acad. Sci. USA (in press).

Johnson, J. W., and S. H. Thompson (1989) Measurement of nonuniform current densities and current kinetics in Aplysia neurons using a large patch method. Biophys. J. 55: 299-308.

Kado, R. T. (1973) Aplysia giant cell: Soma-axon voltage clamp current differences. Science 182: 843-845.

Kamb, A., L. E. Iverson, and M. A. Tanouye (1987) Molecular characterization of Shaker, a Drosophila gene that encodes a potassium channel. Cell 50: 405-413.

Kamb, A., J. Tseng-Cranlk, and M. A. Tanouye (1988) Multiple products of the drosophila Shaker gene may contribute to potassium channel diversity. Neuron $1: 421-430$.

Marquardt, D. W. (1963) An algorithm for least-squares estimation of nonlinear parameters. J. Soc. Adv. Appl. Math. 11: 431-441.

Neher, E. (1971) Two fast transient current components during voltage clamp on snail neurons. J. Gen. Physiol. 58: 36-53.

Pielou, E. C. (1977) Mathernatical Ecology, Wiley, New York.

Poo, M.-M. (1985) Mobility and localization of proteins in excitable membranes. Annu. Rev. Neurosci. 8: 369-406.

Ripley, B. D. (1981) Spatial Statistics, Wiley, New York.

Rudy, B. (1988) Diversity and ubiquity of $\mathrm{K}^{+}$channels. Neuroscience 25: 729-749.

Salkoff, L. B., and R. Wyman (1981a) Outward currents in developing Drosophila flight muscle. Science 212: 461-463.

Salkoff, L. B., and R. Wyman (1981b) Genetic modification of potassium channels in Drosophila Shaker mutants. Nature 293: 228230.

Schwarz, T. L., B. L. Tempel, D. M. Papazian, Y. N. Jan, and L. Y. Jan (1988) Multiple potassium-channel components are produced by alternative splicing at the Shaker locus in Drosophila. Nature 331: 137-142.

Selby, B. (1968) The index of dispersion as a test statistic. Biometrika 52: $627-629$.

Serrano, E. E. (1982) Variability in Molluscan Neuron Soma Currents, Ph.D. Dissertation, Stanford University.

Sokal, R. R., and F. J. Rohlf (1981) Biometry, Freeman, New York.

Solc, C. K., W. N. Zagotta, and R. W. Aldrich (1987) Single channel and genetic analyses reveal two distinct A-type potassium channels in Drosophila. Science 236: 1094-1098.

Stitler, W. M., and G. P. Patil (1969) Variance-to mean ratio and Morisita's Index as measures of spatial patterns in ecological populations. In Statistical Ecology, Vol. 1: Spatial Patterns and Ecological Distributions, G. P. Patil, E. C. Pielou, and W. E. Waters, eds., pp. 421-455, Pennsylvania State University Press.

Strong, J. A. (1984) Modulation of potassium current kinetics in bag cell neurons of Aplysia by an activator of adenylate cyclase. J. Neurosci. 4: 2772-2783.

Strong, J. A., and L. K. Kaczmarek (1986) Multiple components of delayed potassium current in peptidergic neurons of Aplysia: Mod- 
ulation by an activator of adenylate cyclase. J. Neurosci. 6: 814-822.

Tauc, L. (1962) Site of origin and propagation of spikes in the giant neuron of Aplysia. J. Gen. Physiol. 45: 1077-1097.

Taylor, P. S. (1987) Selectivity and patch measurements of A-current channels in Helix aspersa neurones. J. Physiol. (Lond.) 388: 437447.

Tempel, B. L., D. M. Papazian, T. L. Schwarz, Y. N. Jan, and L. Y. Jan (1987) Sequence of a probable potassium channel component encoded at Shaker locus of Drosophila. Science 237: 770-774.

Timpe, L. C., T. L. Schwarz, B. L. Tempel, D. M. Papazian, Y. N. Jan, and L. Y. Jan (1988) Expression of functional potassium channels from Shaker cDNA in Xenopus oocytes. Nature 331: 143-145.

Thompson, S. H. (1977) Three pharmacologically distinct potassium channels in molluscan neurons. J. Physiol. (Lond.) 265: 465-488.

Thompson, S. H., and R. A. Aldrich (1980) Membrane potassium channels. In The Cell Surface and Neuronal Function, C. W. Cotman, G. Poste, and G. I. Nicolson, eds., pp. 50-78, Elsevier/North Holland Biomedical Press, Amsterdam.
Thompson, S. H., and J. Coombs (1988) Spatial distribution of $\mathrm{Ca}$ currents in molluscan neuron cell bodies and regional differences in the strength of inactivation. J. Neurosci. 8: 1929-1939.

$\mathrm{Wu}, \mathrm{C} .-\mathrm{F}$, , and F. N. Haugland (1985) Voltage clamp analysis of membrane currents in larval muscle fibers of Drosophila: Alteration of potassium currents in Shaker mutants. J. Neurosci. 10:2626-2640.

Wu, C.-F., B. Ganetzky, F. N. Haugland, and A. X. Liu (1983) Potassium currents in Drosophila: Different components affected by mutations of two genes. Science 220: 1076-1078.

Zagotta, W. N., M. S. Brainard, and R. W. Aldrich (1988) Singlechannel analysis of four distinct classes of potassium channels in Drosophila muscle. J. Neurosci. 8: 4765-4779. 